\title{
Cytotoxic T-lymphocyte-associated antigen-4 polymorphisms and susceptibility to cervical cancer: A meta-analysis
}

\author{
HAO QIU ${ }^{1 *}$, WEIFENG TANG ${ }^{2 *}$, PENGFEI YIN $^{1},{\text { FENG } \text { CHENG }^{1} \text { and LIXIN WANG }}^{1}$ \\ ${ }^{1}$ Department of Microbiology and Immunology, Medical School of Southeast University, Nanjing, Jiangsu 210008; \\ ${ }^{2}$ Department of Cardiothoracic Surgery, Affiliated People's Hospital of Jiangsu University, \\ Zhenjiang, Jiangsu 212009, P.R. China
}

Received May 28, 2013; Accepted October 7, 2013

DOI: $10.3892 / \mathrm{mmr} .2013 .1721$

\begin{abstract}
Cytotoxic T-lymphocyte associated antigen-4 (CTLA-4) polymorphisms have been examined for associations with cervical cancer in various countries. The results, however, are inconclusive. The present study aimed to explore whether CTLA-4 +49 A/G, -318 C/T and CT60 G/A polymorphisms confer susceptibility to cervical cancer. A meta-analysis was performed with 7,794 subjects included in 15 case-control studies that were published up to January 1, 2013. The results from the meta-analysis indicated that there were no significant associations between the risk of cervical cancer and the three studied polymorphisms [+49 A/G: Odds ratio (OR), 0.94 and $95 \%$ confidence interval $(\mathrm{CI}), 0.82-1.07$ for $\mathrm{GG}+\mathrm{AG}$ vs. AA; -318 C/T: OR, 1.33 and $95 \%$ CI, 0.82-2.16 for TT+TC vs. CC; and CT60: OR, 0.98 and 95\% CI, 0.72-1.33 for AA+AG vs. $\mathrm{GG}$. Stratified analyses by ethnicity for the $+49 \mathrm{~A} / \mathrm{G}$ and $-318 \mathrm{C} / \mathrm{T}$ polymorphisms suggested that Asian populations had a decreased risk of cervical cancer for the $+49 \mathrm{~A} / \mathrm{G}$ polymorphism (OR, 0.75 and 95\% CI, 0.58-0.97 for GG+AG vs. AA), but an increased risk for the $-318 \mathrm{C} / \mathrm{T}$ polymorphism $(\mathrm{OR}, 2.02$ and $95 \% \mathrm{CI}, 1.36-3.00$ for TC vs. CC). In summary, the current meta-analysis showed that the $+49 \mathrm{~A} / \mathrm{G}$ and $-318 \mathrm{C} / \mathrm{T}$ polymorphisms in CTLA-4 constitute risk factors for cervical cancer.
\end{abstract}

\section{Introduction}

Cervical cancer is the third most common type of cancer diagnosed and the fourth leading cause of female cancer mortality

Correspondence to: Dr Lixin Wang, Department of Microbiology and Immunology, Medical School of Southeast University, 87 Ding-jia-qiao Road, Nanjing, Jiangsu 210008, P.R. China

E-mail: 1xwang@seu.edu.cn

*Contributed equally

Abbreviations: CI, confidence interval; OR, odds ratio; CTLA-4, cytotoxic T-lymphocyte associated antigen-4; HWE, Hardy-Weinberg equilibrium; HPV, human papillomavirus

Key words: cervical cancer, gene polymorphism, cytotoxic T-lymphocyte associated antigen-4, meta-analysis worldwide, accounting for $\sim 529,000$ new cancer cases and 275,000 cancer deaths in $2008,>85 \%$ of which occurred in developing countries (1). It is widely accepted that infection by an oncogenic type of human papillomavirus (HPV) is a necessary but not sufficient risk factor for cervical carcinogenesis (2). Various genetic and environmental factors may also play roles in the pathogenesis of or predisposition to cervical cancer, as only a small percentage of infected females develop the cancer (3). Evidence that first-degree relatives of females with cervical cancer have a doubled risk of tumor development distinctly indicates a strong genetic predisposition to the disease (4). The first known cervical cancer susceptibility gene was human leukocyte antigen (HLA)-DQw3 (5). With the development of new technology and invention of new genomic tools, a number of genes outside the $H L A$ region have been examined in patients with cervical cancer across populations of various ethnicities. These include cytotoxic T-lymphocyte-associated antigen-4 (CTLA-4) (6), interleukin-10 (7) and cyclin D1 (8), among other genes.

CTLA-4, also known as cluster of differentiation (CD)152, is a member of the immunoglobulin super family and plays a crucial role in the negative regulation of T-lymphocyte activation and proliferation, indirectly controlling effector T cells (9). The CTLA-4 gene is situated on chromosome $2 \mathrm{q} 33$, close to genes of other regulatory molecules, including CD28 and inducible costimulator (10). It consists of four exons that encode separate functional domains: Leader sequence, and extracellular, transmembrane and cytoplasmic domains (11). In the early stages of tumorigenesis, CTLA-4 may elevate the activation threshold of T-cells, thereby weakening the antitumor response and increasing susceptibility to cancer (12). Studies have shown that CTLA-4 blockade results in enhancement of the immune response (13), rejection (14) or in certain cases, cure of tumors in mice treated with a combination of tumor vaccines (15). Moreover, recent studies have demonstrated that CTLA-4 polymorphisms were associated with susceptibility to cancer (16-19). Thus, it is extremely likely that CTLA-4 polymorphisms are involved in the pathogenesis of cervical cancer. The most frequently studied CTLA-4 polymorphisms are $+49 \mathrm{~A} / \mathrm{G}$ (rs231775), -318 C/T (rs5742909) and CT60 G/A (rs3087243) (6,20-22). A number of studies have been previously performed to determine whether these polymorphisms confer susceptibility to cervical cancer in various populations 
(6,23-29), however, results have been inconclusive. The discrepancy may result from limitations of individual studies, publication bias (30) or yet-unknown effects of the CTLA-4 molecule.

Therefore, with the aim of deriving a more precise assessment of the correlation between $C T L A-4+49 \mathrm{~A} / \mathrm{G},-318 \mathrm{C} / \mathrm{T}$ and CT60 G/A polymorphisms and cervical cancer, a meta-analysis of 15 published case-control studies was performed. To the best of our knowledge, this is the most comprehensive evaluation method with regards to the associations between CTLA-4 polymorphisms and cervical cancer risk.

\section{Subjects and methods}

Study identification and selection. To identify all the published studies that have examined the association of CTLA-4 gene polymorphisms with cervical cancer, the electronic databases of PubMed, Embase and the Chinese Biomedical Database were searched, with the last search update being performed on January 1, 2013. Combinations of keywords, including 'cytotoxic T-lymphocyte associated antigen-4', 'CTLA-4', 'CD152', 'polymorphism' and 'uterine cervical neoplasms' were entered as Medical Subject Headings and text words. No language restriction was applied. References of retrieved articles were also screened. All of the eligible studies were case-control in design, based on unrelated individuals and had available data (distribution of alleles and genotypes for cases and controls) to estimate the odds ratios (ORs) with the $95 \%$ confidence intervals (CIs). Furthermore, genotype distributions in the control groups were required to be in Hardy-Weinberg equilibrium (HWE), according to an exact test.

Data extraction. Data were extracted by two reviewers independently. A consensus was reached following discussion if there was disagreement. The following information was extracted from each eligible study: Author, year of publication, ethnicity of the study population, sample size, genotyping method and genotype number in cases and controls.

Statistical analysis. HWE was tested by an internet-based HWE calculator (http://ihg.gsf.de/cgi-bin/hw/hwa1.pl; accessed March 5, 2013). The strength of associations between the CTLA-4 polymorphisms and cervical cancer risk were evaluated by ORs with the corresponding $95 \%$ CIs. The genetic models that were assessed for pooled ORs of these polymorphisms were dominant models (GG+GA vs. AA for +49 A/G, TT+TC vs. CC for $-318 \mathrm{C} / \mathrm{T}$ and $\mathrm{AA}+\mathrm{AG}$ vs. GG for CT60 G/A). For each CTLA-4 polymorphism, other genetic models (+49 A/G, GG vs. GA+AA, GG vs. AA, GA vs. AA and $\mathrm{G}$ vs. A; $-318 \mathrm{C} / \mathrm{T}$, TT vs. TC+CC, TT vs. CC, TC vs. CC and $\mathrm{T}$ vs. C; and CT60 G/A, AA vs. AG+GG, AA vs. GG, AG vs. GG and A vs. G) were used to evaluate the association with cervical cancer risk.

Statistical heterogeneity among studies was tested with Cochran's Q-statistic, where $\mathrm{P}<0.10$ was considered to indicate a statistically significant difference. The random-effects model (DerSimonian-Laird method) or the fixed-effects model (Mantel-Haenszel method) was used to summarize the combined OR according to the heterogeneity. When
$P \geq 0.10$, the fixed-effects model was used to calculate pooled $\mathrm{OR}$, whereas the random-effects model was used if $\mathrm{P}<0.10$. Significance of the pooled OR was estimated using a Z-test. $\mathrm{P}<0.05$ was considered to indicate a statistically significant difference. Subgroup analyses were performed by ethnic group for the $+49 \mathrm{~A} / \mathrm{G}$ and $-318 \mathrm{C} / \mathrm{T}$ polymorphisms.

Publication bias was checked by the Begg's funnel plot and Egger's test (31). If publication bias existed, the trim and fill method was applied to adjust the results. Statistical manipulations were carried out using Review Manager 5.0 (Cochrane Collaboration, 2008; www.cc-ims.net/RevMan; accessed March 20, 2013) and Stata 12.0 software (StataCorp LP, College Station, TX, USA).

\section{Results}

Study selection and subject characteristics. A total of eight relevant articles investigating CTLA-4 polymorphisms (+49 A/G, -318 C/T and CT60 G/A) and cervical cancer risk met the study inclusion criteria (6,23-29). Fig. 1 shows the detailed procedure for selecting eligible articles. The studies included in the meta-analysis contained 3,684 cervical cancer cases and 4,110 controls. Among the eight articles, seven focused on the $+49 \mathrm{~A} / \mathrm{G}$ polymorphism $(6,23-25,27-29)$, six on the $-318 \mathrm{C} / \mathrm{T}$ polymorphism $(6,24,26-29)$ and two focused on the CT60 G/A polymorphism $(27,29)$. Furthermore, four articles were of Caucasian origin $(6,26-28)$ and four were from an Asian population (23-25,29). In the eight articles, genomic DNA was extracted from peripheral blood samples. For genotyping, various methods were used, including restriction fragment length polymorphism, TaqMan, amplification-refractory mutation system and multiplex polymerase chain reaction with hybridization and Sequenom MassArray. Characteristics of each article included in this meta-analysis are summarized in Table I and the genotype numbers are listed in Table II.

\section{Quantitative synthesis}

+49 A/G polymorphism. In total, 2,398 cervical cancer cases and 3,546 controls from 7 case-control studies were included in the meta-analysis of the association between CTLA-4 +49 A/G polymorphism and cervical cancer (6,23-25,27-29). Of these, 4 case-control studies were from an Asian population $(23-25,29)$ and 3 from a Caucasian population $(6,27,28)$. As shown in Fig. 2, the heterogeneity of GG+AG vs. AA was tested for the 7 case-control studies. Data from the meta-analysis were as follows: $\chi^{2}, 9.41$, degrees of freedom (df), 6 and $\mathrm{P}=0.152$ in a fixed-effects model. $\mathrm{I}^{2}$ value, an additional heterogeneity indicator, was $36.2 \%$, indicating low heterogeneity. Therefore, the fixed-effects model was used for the synthesis of data. The results obtained showed no association between overall cervical cancer risk and the $C T L A-4+49 \mathrm{~A} / \mathrm{G}$ polymorphism (OR, 0.94, 95\% CI, 0.82-1.07 and $\mathrm{P}=0.349$ for GG+AG vs. AA; Fig. 2). In subgroup analysis, significantly decreased cervical cancer risks were found in Asians (OR, 0.75, 95\% CI, 0.58-0.97 and $\mathrm{P}=0.028$ for $\mathrm{GG}+\mathrm{AG}$ vs. AA), but not in Caucasians (OR, 1.02, 95\% CI, 0.87-1.20 and $\mathrm{P}=0.775$ for GG+AG vs. AA; Fig. 3). Other comparison results are listed in Table III. No publication bias was detected by Begg's funnel plot or Egger's test $(P>|t|=0.809$; Fig. 8). 
Table I. Characteristics of the individual studies included in the meta-analysis.

\begin{tabular}{|c|c|c|c|c|c|}
\hline Study & Year & Country (ethnicity) & $\begin{array}{l}\text { Sample size, } \\
\text { case/control }\end{array}$ & Genotype method & Polymorphisms \\
\hline Li et al (23) & 2011 & China (Asians) & $314 / 320$ & RFLP & $+49 \mathrm{~A} / \mathrm{G}$ \\
\hline Jiang et al (24) & 2011 & China (Asians) & $100 / 100$ & Sequenom MassArray & $+49 \mathrm{~A} / \mathrm{G},-318 \mathrm{C} / \mathrm{T}$ \\
\hline Rahimifar et al (6) & 2010 & Iran (Caucasians) & $55 / 110$ & RFLP, PCR-ARMS & $+49 \mathrm{~A} / \mathrm{G},-318 \mathrm{C} / \mathrm{T}$ \\
\hline Hu et al (25) & 2010 & China (Asians) & $696 / 709$ & TaqMan & $+49 \mathrm{~A} / \mathrm{G}$ \\
\hline Ivansson et al (26) & 2010 & Sweden (Caucasians) & $1,281 / 554$ & TaqMan & $-318 \mathrm{C} / \mathrm{T}$ \\
\hline Pawlak et al (27) & 2010 & Poland (Caucasians) & $141 / 224$ & RFLP & $\begin{array}{l}+49 \mathrm{~A} / \mathrm{G},-318 \mathrm{C} / \mathrm{T}, \\
\text { CT60 G/A }\end{array}$ \\
\hline Castro et al (28) & 2009 & Sweden (Caucasians) & $953 / 1,715$ & $\begin{array}{l}\text { Multiplex PCR } \\
\text { with hybridization }\end{array}$ & $+49 \mathrm{~A} / \mathrm{G},-318 \mathrm{C} / \mathrm{T}$ \\
\hline Su et al (29) & 2007 & Taiwan (Asians) & $144 / 378$ & RFLP & $\begin{array}{l}+49 \mathrm{~A} / \mathrm{G},-318 \mathrm{C} / \mathrm{T}, \\
\text { CT60 G/A }\end{array}$ \\
\hline
\end{tabular}

RFLP, restriction fragment length polymorphism; PCR, polymerase chain reaction; ARMS, amplification-refractory mutation system.

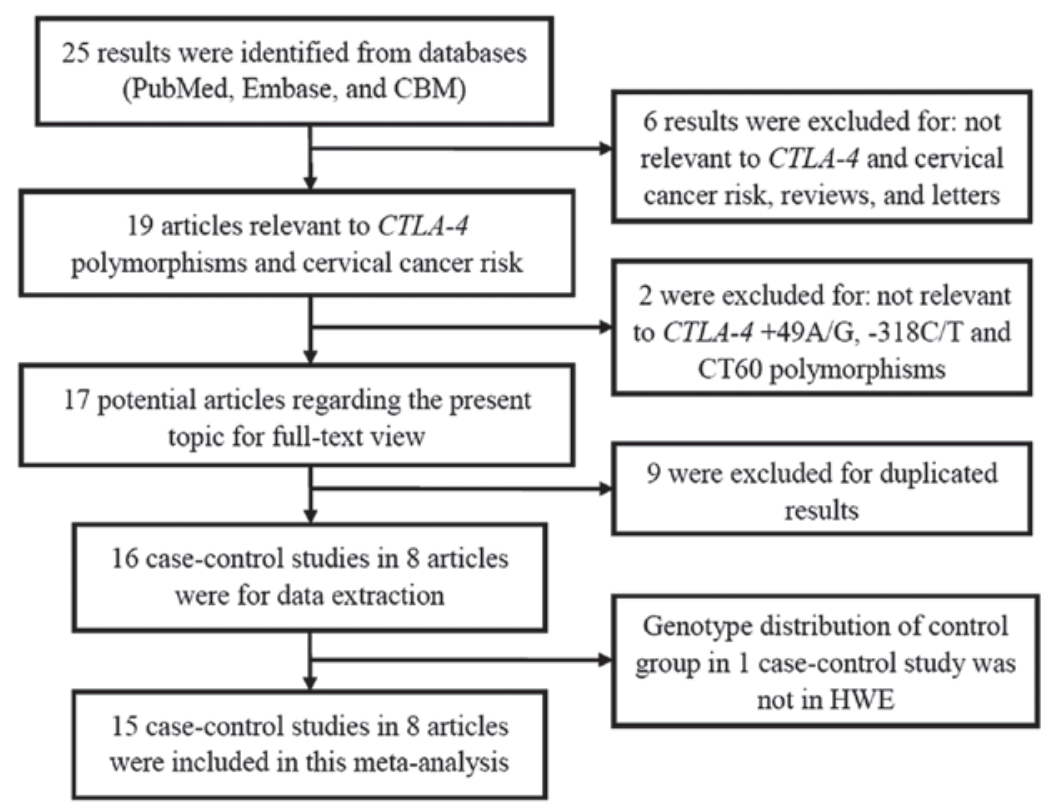

Figure 1. Flow diagram of the article selection process for CTLA-4 gene polymorphisms and cervical cancer risk meta-analysis. CTLA-4, cytotoxic T-lymphocyte-associated antigen- 4 .

-318 C/T polymorphism. A total of 2,667 cases and 3,058 controls from 6 case-control studies were included in the meta-analysis of the correlation between the $-318 \mathrm{C} / \mathrm{T}$ polymorphism and cervical cancer (6,24,26-29). Two case-control studies were from an Asian population $(24,29)$ and 4 from a Caucasian population $(6,26-28)$. As shown in Fig. 4, the heterogeneity of TT+TC vs. CC was evaluated for the 6 case-control studies. Data from the meta-analysis were as follows: $\chi^{2}, 19.82$, df, 5 and $\mathrm{P}=0.001$ in a random-effects model. Additionally, $\mathrm{I}^{2}$ value was $74.8 \%$, indicating moderated heterogeneity. Thus, the random-effects model was used for the synthesis of data. No statistical evidence of an association between the $-318 \mathrm{C} / \mathrm{T}$ polymorphism and cervical cancer risks
(OR, 1.33, 95\% CI, 0.82-2.16 and $\mathrm{P}=0.249$ for TT+TC vs. CC; Fig. 4) was observed. In the subgroup analysis, significantly increased cervical cancer risks were observed in the Asian population (OR, 2.02, 95\% CI, 1.36-3.00 and $\mathrm{P}=0.000$ for TC vs. CC; Fig. 5), but not in the Caucasian population (OR, 0.98, 95\% CI, 0.53-1.81 and P=0.950 for TC vs. CC; Fig. 6). Other comparison results are listed in Table III. No publication bias was detected by Begg's funnel plot or Egger's test $(\mathrm{P}>|\mathrm{t}|=0.989$; Fig. 9).

CT60 G/A polymorphism. A total of 253 cases and 602 controls from 2 case-control studies were included in the meta-analysis of the correlation between the CT60 G/A polymorphism and cervical cancer $(27,29)$. One case-control 
Table II. Distribution of CTLA-4 polymorphism genotypes and alleles among cervical cancer patients and controls.

A, Polymorphism +49 A/G

\begin{tabular}{|c|c|c|c|c|c|c|c|c|c|c|c|}
\hline \multirow[b]{2}{*}{ Study } & \multicolumn{3}{|c|}{ Case } & \multicolumn{3}{|c|}{ Control } & \multicolumn{2}{|c|}{ Case } & \multicolumn{2}{|c|}{ Control } & \multirow[b]{2}{*}{ HWE } \\
\hline & AA & $\mathrm{AG}$ & GG & AA & $\mathrm{AG}$ & GG & G & A & G & A & \\
\hline Li et al (23) & 30 & 144 & 140 & 18 & 129 & 173 & 424 & 204 & 475 & 165 & Yes \\
\hline Jiang et al (24) & 13 & 42 & 45 & 19 & 39 & 42 & 132 & 68 & 123 & 77 & Yes \\
\hline Rahimifar et al (6) & 28 & 27 & 0 & 58 & 45 & 7 & 27 & 83 & 59 & 161 & Yes \\
\hline Hu et al (25) & 80 & 290 & 326 & 56 & 300 & 353 & 942 & 450 & 1,006 & 412 & Yes \\
\hline Pawlak et al (27) & 43 & 72 & 26 & 71 & 103 & 43 & 124 & 158 & 189 & 245 & Yes \\
\hline Castro et al (28) & 252 & 449 & 252 & 456 & 825 & 434 & 953 & 953 & 1,693 & 1,737 & Yes \\
\hline Su et al (29) & 17 & 62 & 60 & 42 & 155 & 178 & 182 & 96 & 511 & 239 & Yes \\
\hline
\end{tabular}

B, Polymorphism -318 C/T

\begin{tabular}{|c|c|c|c|c|c|c|c|c|c|c|c|}
\hline \multirow[b]{2}{*}{ Study } & \multicolumn{3}{|c|}{ Case } & \multicolumn{3}{|c|}{ Control } & \multicolumn{2}{|c|}{ Case } & \multicolumn{2}{|c|}{ Control } & \multirow[b]{2}{*}{ HWE } \\
\hline & $\mathrm{CC}$ & $\mathrm{TC}$ & TT & $\mathrm{CC}$ & $\mathrm{TC}$ & TT & $\mathrm{C}$ & $\mathrm{T}$ & $\mathrm{C}$ & $\mathrm{T}$ & \\
\hline Jiang et al (24) & 75 & 24 & 1 & 92 & 8 & 0 & 174 & 26 & 192 & 8 & Yes \\
\hline Rahimifar et al (6) & 51 & 3 & 0 & 89 & 20 & 1 & 105 & 3 & 198 & 22 & Yes \\
\hline Ivansson et al (26) & 1,044 & 228 & 9 & 458 & 92 & 4 & 2,316 & 246 & 1,008 & 100 & Yes \\
\hline Pawlak et al (27) & 99 & 38 & 3 & 180 & 35 & 1 & 236 & 44 & 395 & 37 & Yes \\
\hline Castro et al (28) & 5 & 124 & 819 & 6 & 223 & 1,471 & 134 & 1,762 & 235 & 3,165 & Yes \\
\hline Su et al (29) & 105 & 38 & 1 & 306 & 67 & 5 & 248 & 40 & 679 & 77 & Yes \\
\hline
\end{tabular}

C, Polymorphism CT60 G/A

\begin{tabular}{|c|c|c|c|c|c|c|c|c|c|c|c|}
\hline \multirow[b]{2}{*}{ Study } & \multicolumn{3}{|c|}{ Case } & \multicolumn{3}{|c|}{ Control } & \multicolumn{2}{|c|}{ Case } & \multicolumn{2}{|c|}{ Control } & \multirow[b]{2}{*}{ HWE } \\
\hline & GG & GA & AA & GG & GA & $\mathrm{AA}$ & G & A & G & A & \\
\hline Pawlak et al (27) & 41 & 58 & 15 & 77 & 104 & 43 & 140 & 88 & 258 & 190 & Yes \\
\hline Su et al (29) & 87 & 45 & 7 & 238 & 123 & 17 & 219 & 59 & 599 & 157 & Yes \\
\hline
\end{tabular}

HWE, Hardy-Weinberg equilibrium. CTLA-4, cytotoxic T-lymphocyte-associated antigen-4.

study was from a Caucasian population (27) and the other from an Asian population (29). The results showed no statistical evidence of an association between the CT60 G/A polymorphism and the overall cervical cancer risk (OR, 0.98, 95\% CI, 0.72-1.33 and $\mathrm{P}=0.898$ for AA+GA vs. GG; Fig. 7). Further subgroup analysis was not performed due to the limited data for this polymorphism. Other comparison results are listed in Table III.

\section{Discussion}

Cervical cancer is a complex malignant tumor that affects female reproductive organs and has a number of genetic and environmental determinants. Specific oncogenic HPV is an important etiologic agent in cervical cancer. However, HPV infection alone is insufficient in inducing malignant changes (2). Host genetic factors may be important in cervical cancer susceptibility. CTLA-4, one of the key mediators for inhibiting activated T-lymphocytes, plays a pivotal role in cancer immunosurveillance (13). Considering the importance of CTLA-4, variations in this gene may affect the risk of developing cervical cancer. In addition, the effect of gene polymorphisms involved in tumorigenesis or susceptibility to cervical cancer has gained increasing interest in previous years. Specific studies have reported an association between genetic risk factors and cervical cancer $(6-8,23,24,32)$. Rahimifar et al (6) observed that at the -318 locus in $C T L A-4$, higher C allele frequency, as well as increased frequency of -318 CC genotype, was found in patients with cervical cancer when compared with controls. However, this association was from a study with a small sample size and was restricted to females in Iran. Li et al (23) showed that Chinese females with the +49 AA genotype have a 2.06-fold higher risk of developing cervical cancer compared with GG carriers. In addition, Jiang et al (24) observed that a 


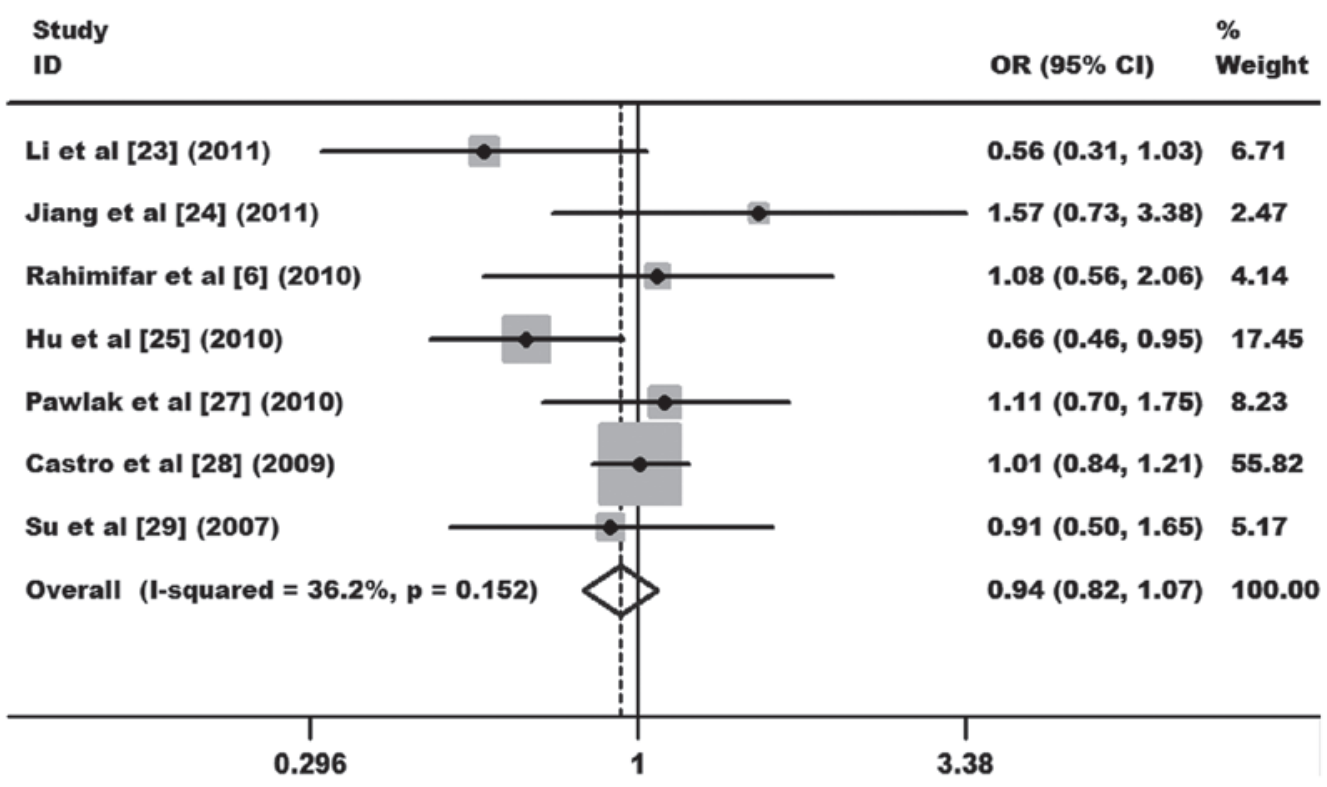

Figure 2. Meta-analysis with a fixed-effects model for the association between the risk of developing cervical cancer and the CTLA-4 +49 A/G polymorphism (GG+AG vs. AA). CTLA-4, cytotoxic T-lymphocyte-associated antigen-4.

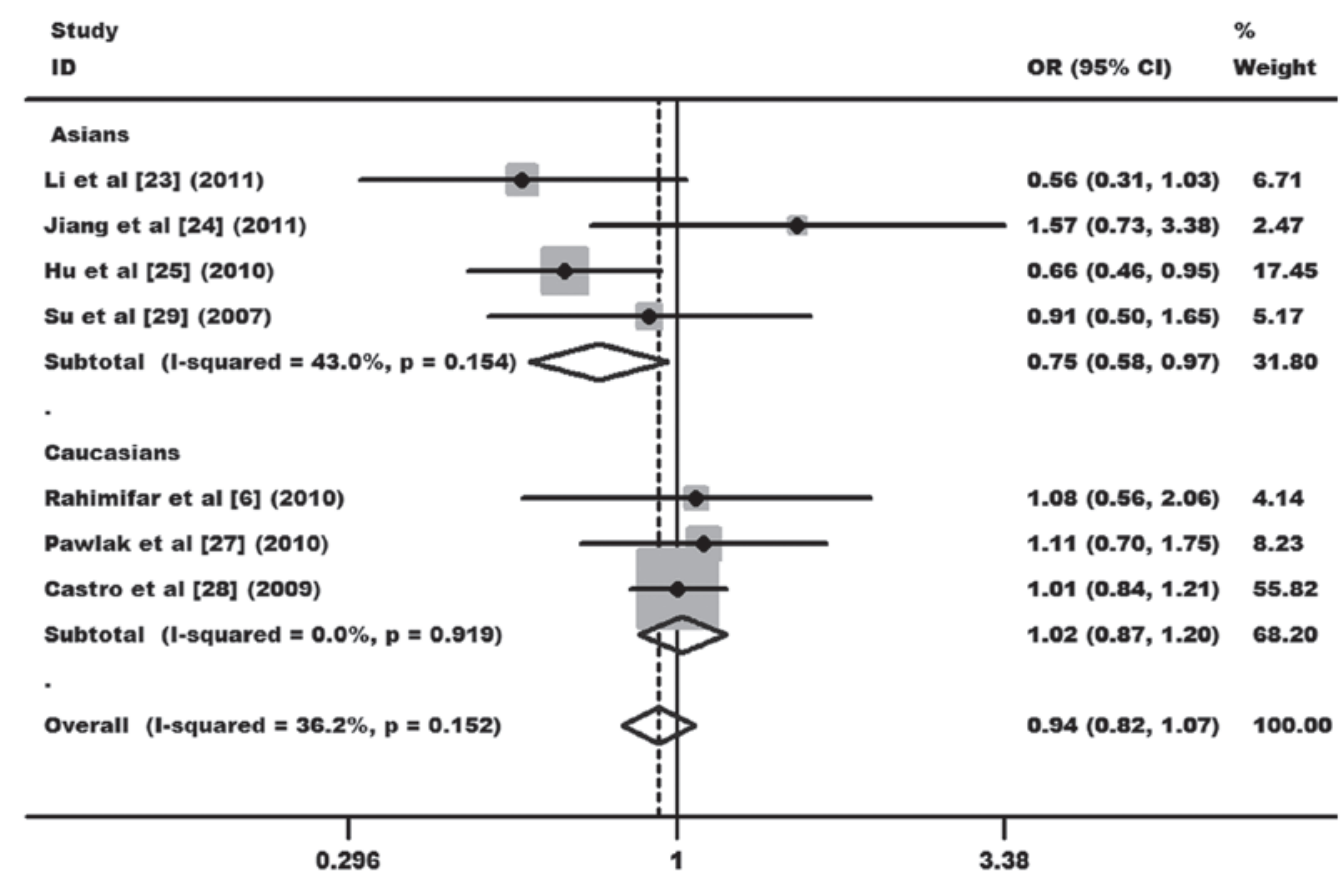

Figure 3. Meta-analysis with a fixed-effects model for the association between the risk of developing cervical cancer and the CTLA-4 +49 A/G polymorphism (GG+AG vs. AA). Subgroup analysis by ethnicity. CTLA-4, cytotoxic T-lymphocyte-associated antigen- 4 .

single-nucleotide polymorphism in the promoter region of the CTLA-4 gene may increase susceptibility to cervical cancer. However, negative results were also obtained in certain studies, due to conflicting observations and the limited sample size of individual studies. Alternatively, meta-analysis is a strategy to reduce the limitations of individual studies and is often applied in genetic association studies. Thus, meta-analysis was used in the present study to assess whether an association exists between the most commonly studied polymorphisms of the CTLA-4 gene, $+49 \mathrm{~A} / \mathrm{G},-318 \mathrm{C} / \mathrm{T}$ and CT60 G/A and the risk of developing cervical cancer.
A total of 15 case-control studies from 8 articles, comprising 3,684 cervical cancer cases and 4,110 controls, were included in the meta-analysis. The results indicated no association of CTLA-4 +49 A/G, -318 C/T and CT60 G/A polymorphisms with overall cervical cancer risk. Furthermore, stratification by ethnicity showed that Asian individuals with GG/AG genotypes had a significantly decreased cervical cancer risk compared with AA carriers for the $+49 \mathrm{~A} / \mathrm{G}$ polymorphism. By contrast, for the $-318 \mathrm{C} / \mathrm{T}$ polymorphism, an increased cervical cancer risk was observed for the TC genotype, compared with $\mathrm{CC}$ carriers. However, the results should be interpreted with 
Table III. Summary of results of the meta-analysis from various comparative genetic models.

A, Polymorphism $+49 \mathrm{~A} / \mathrm{G}$

\begin{tabular}{|c|c|c|c|c|}
\hline \multirow[b]{2}{*}{ Genetic comparison } & \multirow[b]{2}{*}{ Population } & \multirow[b]{2}{*}{ OR (95\% CI); P-value } & \multicolumn{2}{|c|}{ Test of heterogeneity } \\
\hline & & & P-value; I ${ }^{2}(\%)$ & Model \\
\hline \multirow[t]{3}{*}{ GG+AG vs. AA } & All & 0.94 (0.82-1.07); 0.349 & $0.152 ; 36.2$ & $\mathrm{~F}$ \\
\hline & Asian & 0.75 (0.58-0.97); 0.028 & $0.154 ; 43.0$ & $\mathrm{~F}$ \\
\hline & Caucasian & $1.02(0.87-1.20) ; 0.775$ & $0.919 ; 0.0$ & $\mathrm{~F}$ \\
\hline \multirow[t]{3}{*}{$\mathrm{GG}$ vs. $\mathrm{AA}+\mathrm{AG}$} & All & 0.92 (0.82-1.03); 0.154 & $0.201 ; 29.8$ & $\mathrm{~F}$ \\
\hline & Asian & 0.84 (0.72-0.98); 0.028 & $0.389 ; 0.6$ & $\mathrm{~F}$ \\
\hline & Caucasian & 1.03 (0.87-1.22); 0.754 & $0.307 ; 15.3$ & $\mathrm{~F}$ \\
\hline \multirow[t]{3}{*}{ GG vs. AA } & All & 0.84 (0.62-1.12); 0.234 & $0.057 ; 51.0$ & $\mathrm{R}$ \\
\hline & Asian & 0.71 (0.54-0.92); 0.011 & $0.141 ; 45.1$ & $\mathrm{~F}$ \\
\hline & Caucasian & $1.02(0.83-1.25) ; 0.833$ & $0.384 ; 0.0$ & $\mathrm{~F}$ \\
\hline \multirow[t]{3}{*}{ AG vs. AA } & All & 0.95 (0.82-1.10); 0.482 & $0.310 ; 15.7$ & $\mathrm{~F}$ \\
\hline & Asian & 0.79 (0.61-1.04); 0.093 & $0.257 ; 25.7$ & $\mathrm{~F}$ \\
\hline & Caucasian & 1.02 (0.86-1.21); 0.812 & $0.695 ; 0.0$ & $\mathrm{~F}$ \\
\hline \multirow[t]{3}{*}{ G vs. A } & All & 0.94 (0.87-1.02); 0.133 & $0.120 ; 40.6$ & $\mathrm{~F}$ \\
\hline & Asian & 0.85 (0.76-0.96); 0.007 & $0.190 ; 37.0$ & $\mathrm{~F}$ \\
\hline & Caucasian & 1.02 (0.92-1.13); 0.716 & $0.870 ; 0.0$ & $\mathrm{~F}$ \\
\hline
\end{tabular}

B, Polymorphism -318 C/T

\begin{tabular}{|c|c|c|c|c|}
\hline \multirow[b]{2}{*}{ Genetic comparison } & \multirow[b]{2}{*}{ Population } & \multirow[b]{2}{*}{ OR (95\% CI); P-value } & \multicolumn{2}{|c|}{ Test of heterogeneity } \\
\hline & & & P-value; I² (\%) & Model \\
\hline \multirow[t]{3}{*}{ TT+TC vs. CC } & All & $1.33(0.82-2.16) ; 0.249$ & $0.001 ; 74.8$ & $\mathrm{R}$ \\
\hline & Asian & $2.28(0.97-5.38) ; 0.060$ & $0.070 ; 69.5$ & $\mathrm{R}$ \\
\hline & Caucasian & $0.97(0.51-1.85) ; 0.930$ & $0.008 ; 74.6$ & $\mathrm{R}$ \\
\hline \multirow[t]{3}{*}{ TT vs. TC+CC } & All & $1.00(0.80-1.25) ; 0.982$ & $0.752 ; 0.0$ & $\mathrm{~F}$ \\
\hline & Asian & $0.90(0.18-4.45) ; 0.901$ & $0.373 ; 0.0$ & $\mathrm{~F}$ \\
\hline & Caucasian & $1.00(0.80-1.26) ; 0.967$ & $0.603 ; 0.0$ & $\mathrm{~F}$ \\
\hline \multirow[t]{3}{*}{ TT vs. CC } & All & $1.04(0.53-2.03) ; 0.917$ & $0.613 ; 0.0$ & $\mathrm{~F}$ \\
\hline & Asian & $1.05(0.21-5.11) ; 0.955$ & $0.351 ; 0.0$ & $\mathrm{~F}$ \\
\hline & Caucasian & 1.03 (0.49-2.18); 0.929 & $0.441 ; 0.0$ & $\mathrm{~F}$ \\
\hline \multirow[t]{3}{*}{ TC vs. CC } & All & $1.34(0.83-2.15) ; 0.232$ & $0.003 ; 72.7$ & $\mathrm{R}$ \\
\hline & Asian & $2.02(1.36-3.00) ; 0.000$ & $0.105 ; 62.0$ & $\mathrm{~F}$ \\
\hline & Caucasian & $0.98(0.53-1.81) ; 0.950$ & $0.015 ; 71.2$ & $\mathrm{R}$ \\
\hline \multirow[t]{3}{*}{ T vs. C } & All & $1.29(0.90-1.83) ; 0.161$ & $0.001 ; 77.2$ & $\mathrm{R}$ \\
\hline & Asian & $2.11(0.86-5.18) ; 0.105$ & $0.047 ; 74.7$ & $\mathrm{R}$ \\
\hline & Caucasian & 1.08 (0.74-1.59); 0.687 & $0.005 ; 76.3$ & $\mathrm{R}$ \\
\hline \multicolumn{5}{|c|}{ C, Polymorphism CT60 G/A } \\
\hline \multirow[b]{2}{*}{ Genetic comparison } & \multirow[b]{2}{*}{ Population } & \multirow[b]{2}{*}{ OR (95\% CI); P-value } & \multicolumn{2}{|c|}{ Test of heterogeneity } \\
\hline & & & P-value; $\mathrm{I}^{2}(\%)$ & Model \\
\hline $\mathrm{AA}+\mathrm{AG}$ vs. GG & All & $0.98(0.72-1.33) ; 0.898$ & $0.786 ; 0.0$ & $\mathrm{~F}$ \\
\hline AA vs. AG+GG & All & $0.76(0.45-1.28) ; 0.308$ & $0.313 ; 1.9$ & $\mathrm{~F}$ \\
\hline AA vs. GG & All & $0.80(0.46-1.39) ; 0.420$ & $0.356 ; 0.0$ & $\mathrm{~F}$ \\
\hline AG vs. GG & All & $1.02(0.74-1.41) ; 0.904$ & $0.891 ; 0.0$ & $\mathrm{~F}$ \\
\hline A vs. G & All & $0.93(0.74-1.18) ; 0.565$ & $0.437 ; 0.0$ & $\mathrm{~F}$ \\
\hline
\end{tabular}

OR, odds ratio; CI, confidence interval; F, fixed model; R, random model. 


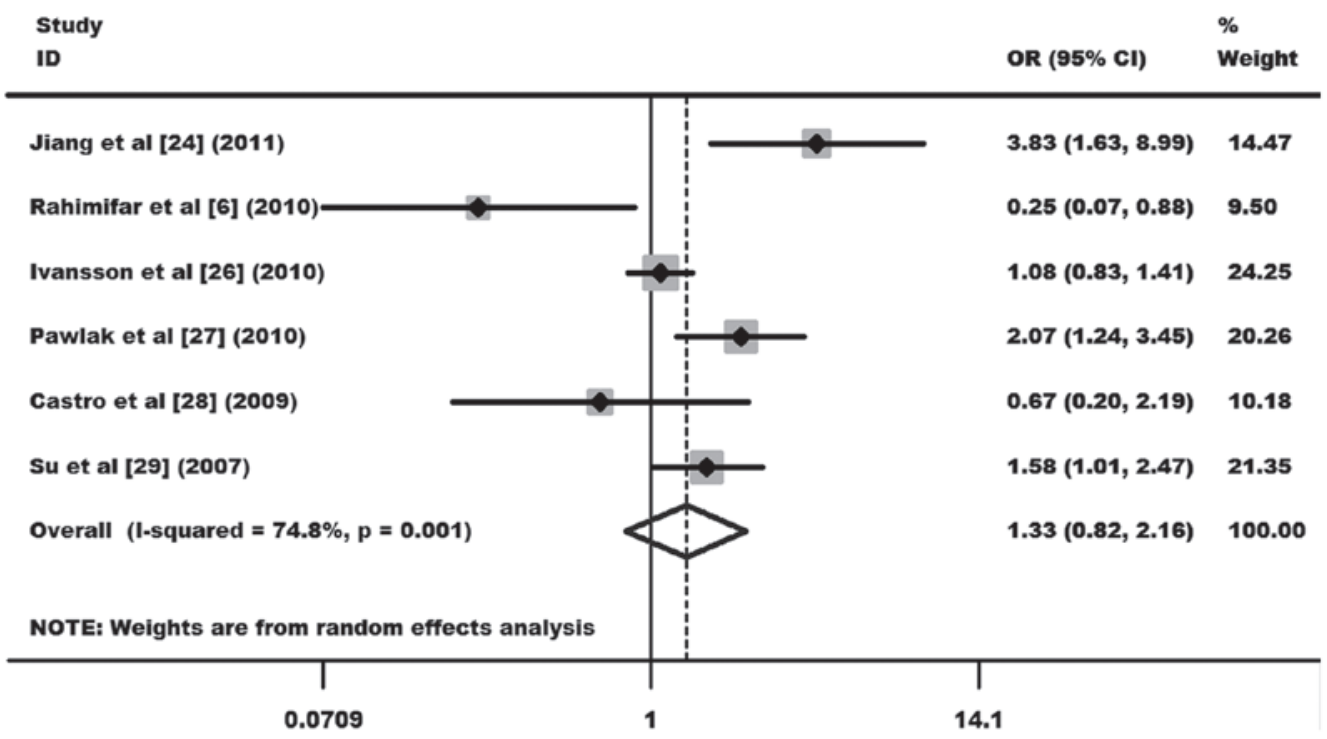

Figure 4. Meta-analysis with a random-effects model for the association between the risk of developing cervical cancer and the CTLA-4 -318 C/T polymorphism (TT+TC vs. CC). CTLA-4, cytotoxic T-lymphocyte-associated antigen-4.

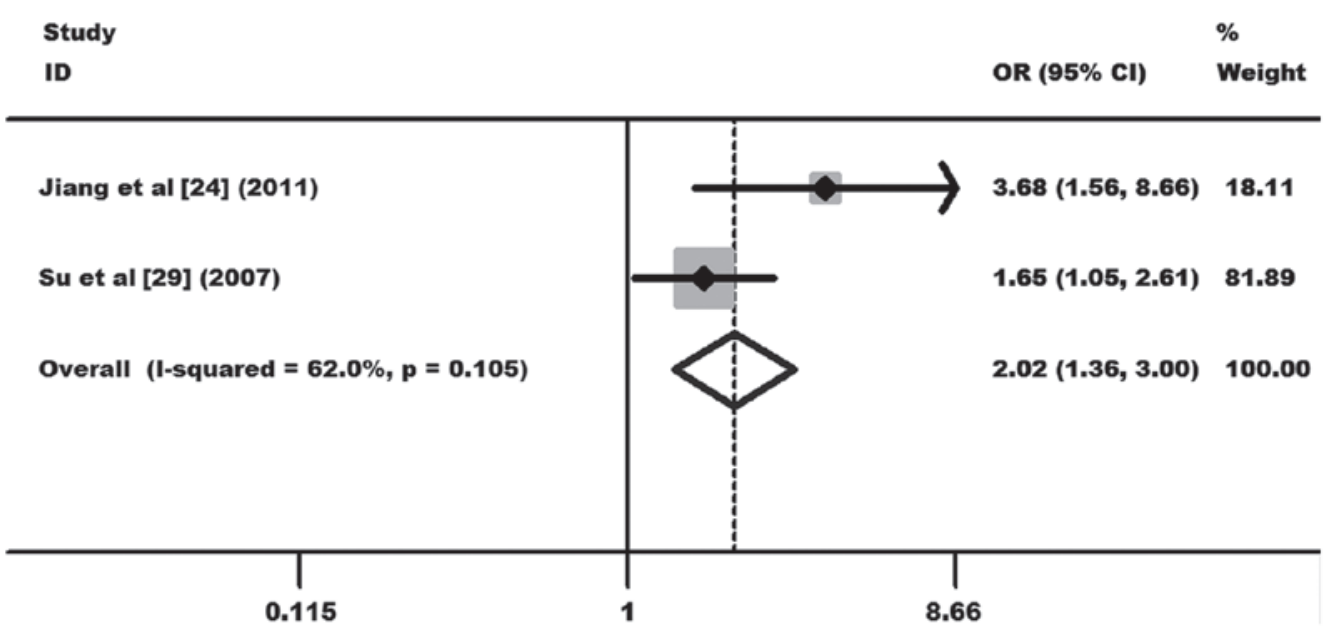

Figure 5. Meta-analysis with a fixed-effects model for the association between the risk of developing cervical cancer and the CTLA-4 $-318 \mathrm{C} / \mathrm{T}$ polymorphism (TC vs. CC) in an Asian population. CTLA-4, cytotoxic T-lymphocyte-associated antigen-4.

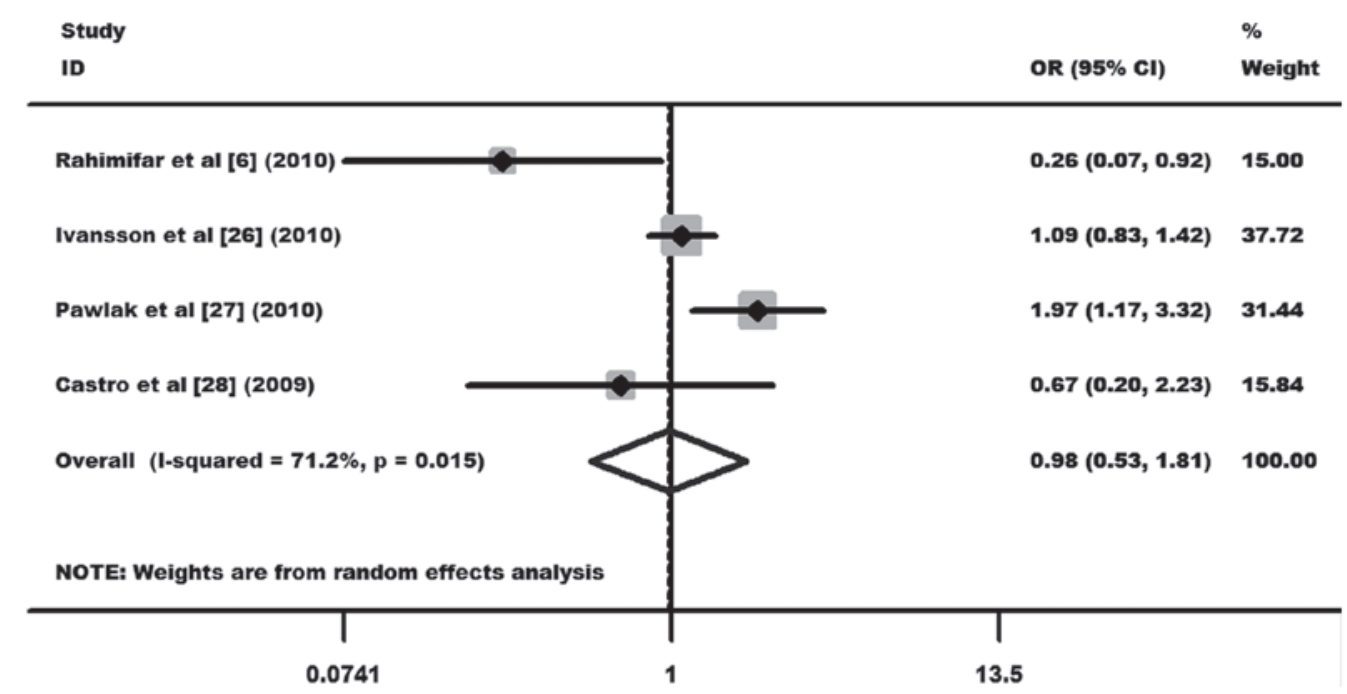

Figure 6. Meta-analysis with a random-effects model for the association between the risk of developing cervical cancer and the CTLA-4 $-318 \mathrm{C} / \mathrm{T}$ polymorphism (TC vs. CC) in a Caucasian population. CTLA-4, cytotoxic T-lymphocyte-associated antigen-4. 


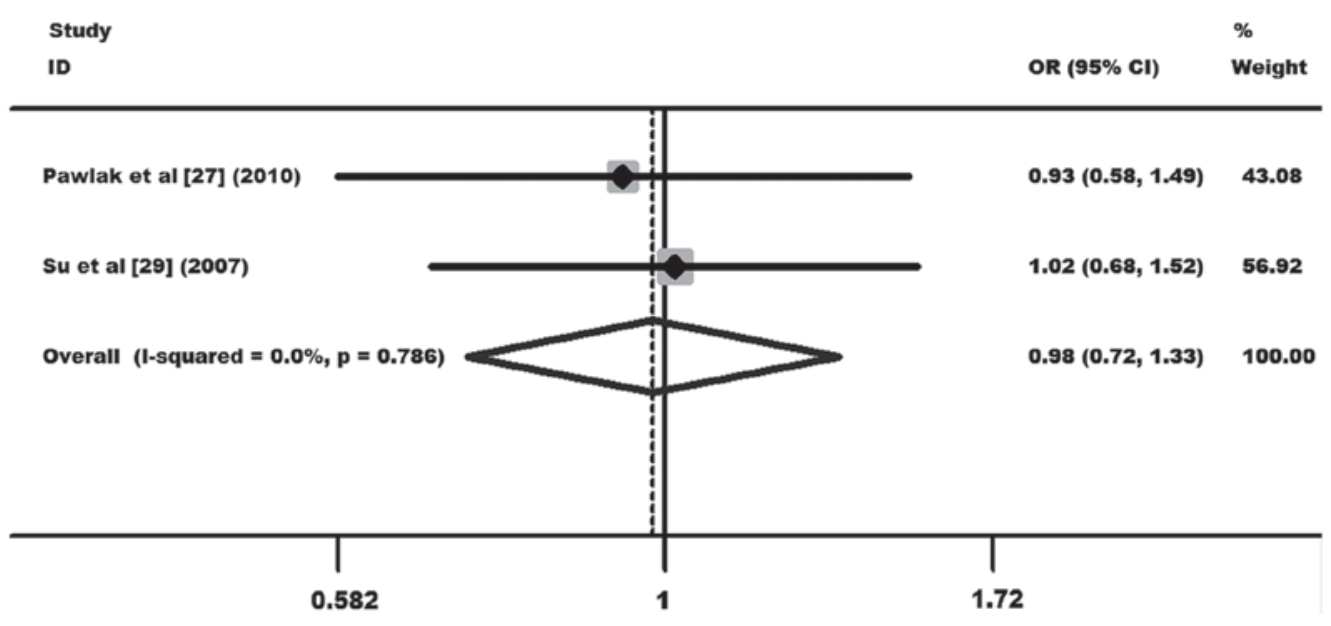

Figure 7. Meta-analysis with a fixed-effects model for the association between the risk of developing cervical cancer and the CTLA-4 CT60 G/A polymorphism (AA+AG vs. GG). CTLA-4, cytotoxic T-lymphocyte-associated antigen-4.

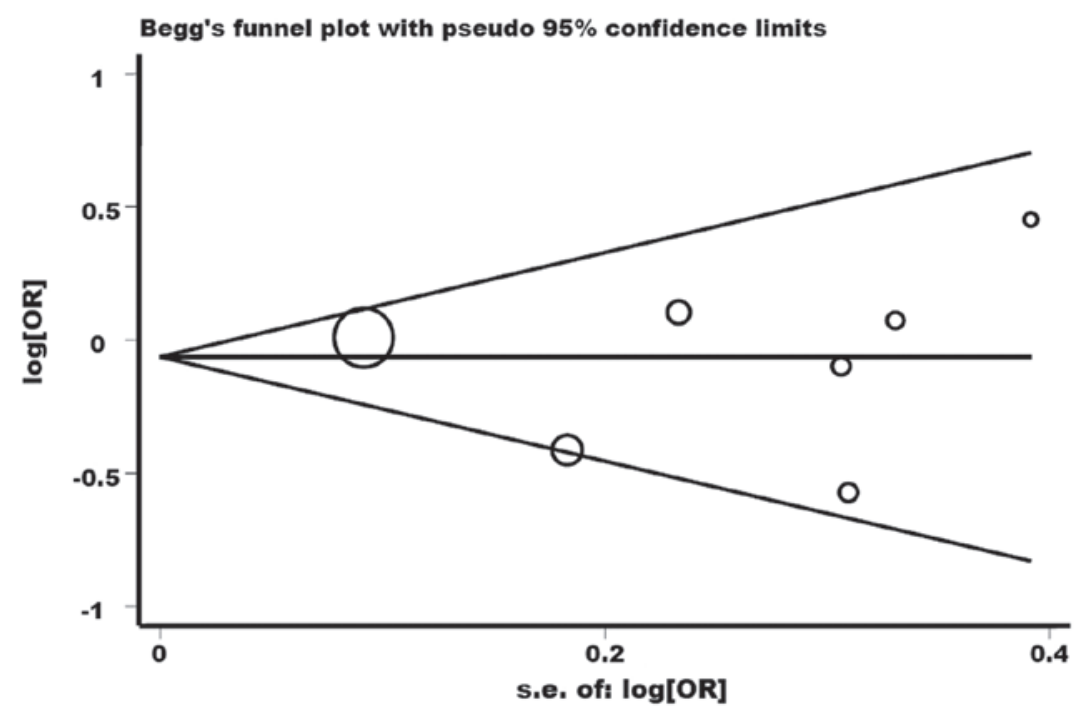

Figure 8. Begg's funnel plot of studies examining the association between the CTLA-4 $+49 \mathrm{~A} / \mathrm{G}$ polymorphism and cervical cancer for overall studies in the dominant model. CTLA-4, cytotoxic T-lymphocyte-associated antigen-4.

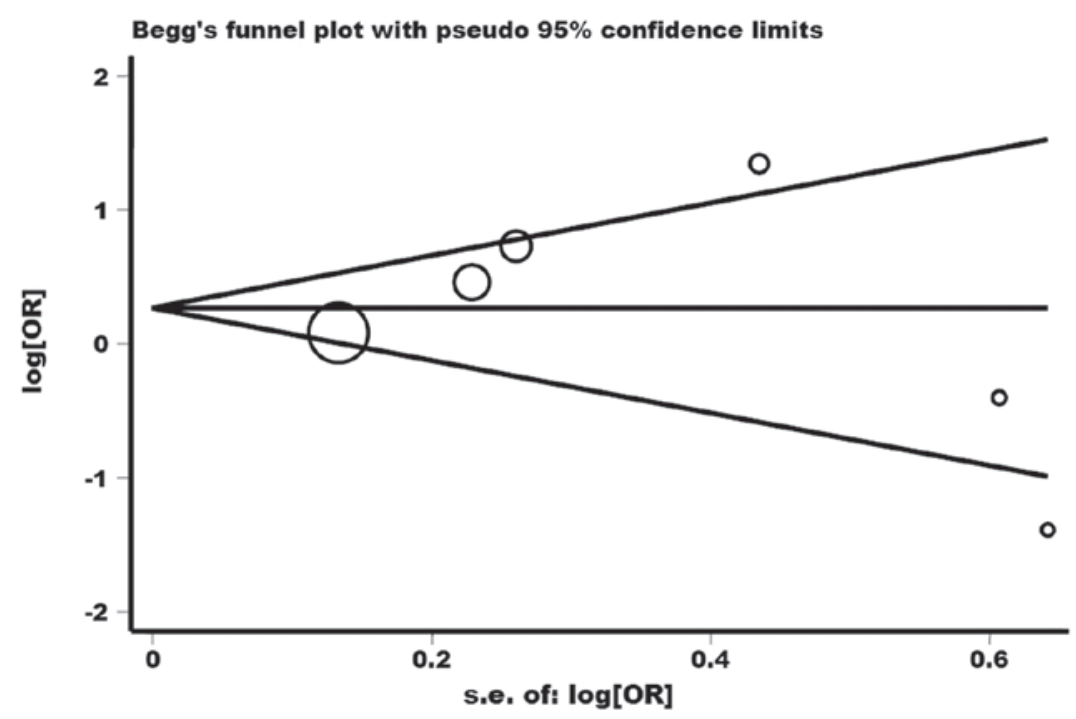

Figure 9. Begg's funnel plot of studies examining the association between the CTLA-4 -318 C/T polymorphism and cervical cancer for overall studies in the dominant model. CTLA-4, cytotoxic T-lymphocyte-associated antigen-4. 
caution, as only two case-control studies were included in an Asian population for the $-318 \mathrm{C} / \mathrm{T}$ polymorphism, which may have limited the statistical power to reveal a reliable association. Therefore, future studies are required to validate the association. The present meta-analysis found that the $+49 \mathrm{~A} / \mathrm{G}$ polymorphism correlated with a decreased risk for cervical cancer among Asian but not Caucasian individuals, while the $-318 \mathrm{C} / \mathrm{T}$ polymorphism correlated with an increased risk among Asian but not Caucasian individuals. These observations suggest that interactions between genetic diversity in various ethnicities and genetic variants may contribute to various risks of cervical cancer.

Since $\mathrm{Su}$ et al (29) reported that the $-318 \mathrm{C} / \mathrm{T}$ variant in the promoter region of the CTLA-4 gene was associated with HPV-16-associated cervical squamous cell carcinoma in Taiwanese females in 2007, more studies have focused on the association between CTLA-4 polymorphisms and cervical cancer. However, certain results have been conflicting. In the current meta-analysis, eight eligible articles published up to January 1, 2013 were considered, comprising a total of 7,794 subjects. Thus, the statistical analysis of the present study may provide more powerful evidence of an association. Moreover, it was found that the CTLA-4 +49 A/G and $-318 \mathrm{C} / \mathrm{T}$ polymorphisms may play various roles in cervical cancer susceptibility across various populations, indicating that the associations may be ethnicity-specific. In the future, a large number of studies are required to analyze these associations in diverse ethnicities.

Heterogeneity and publication bias are two important issues that should be addressed, as they may have affected the results of the meta-analysis. Heterogeneity was observed between studies for the $+49 \mathrm{~A} / \mathrm{G}$ and $-318 \mathrm{C} / \mathrm{T}$ polymorphisms, in overall comparisons in the dominant model. However, when stratification by ethnicity was employed, heterogeneity decreased or was removed in specific subgroups, indicating various roles for genetic backgrounds, even for the same polymorphism. Significant publication bias was not detected for the three polymorphisms, indicating the reliability of the results from this meta-analysis.

To a certain extent, several limitations may have affected the results of the present study and should be considered when interpreting the results. Firstly, the limited study sample size of certain participants may have weakened the statistical power to evaluate the association between CTLA-4 polymorphisms and cervical cancer. Secondly, the number of studies included in the meta-analysis was relatively small, which prevented further subgroup analysis for the CT60 G/A polymorphism. Furthermore, on account of the small amount of data available for each included study, it was not possible to conduct a subgroup analysis by other covariates, including HPV subtype and status, grade of differentiation of cervical cancer, lifestyle and environmental factors. Some of these variables are documented as important risk factors for cervical cancer (33). Thirdly, since all studies for data analysis were from Asian and Caucasian populations, the results may only be applicable to these two ethnic groups. Additionally, eligible articles were identified from the selected databases; thus, specific published articles concerning the current topic or unpublished articles which had negative observations were missed, which may have distorted the analysis.
In conclusion, in spite of the several aforementioned limitations, results from the meta-analysis suggest that the CTLA-4 +49 A/G and -318 C/T polymorphisms, but not the CT60 G/A polymorphism, may be risk factors for cervical cancer. In the future, more intensive studies based on various ethnicities are required to further the understanding of gene-gene and gene-environment interactions between $C T L A-4$ polymorphisms and cervical cancer risk.

\section{Acknowledgements}

This work was funded by the National Natural Science Foundation of China (31170857, 30972783; http://www.nsfc. gov.cn/Portal0/default166.htm). The authors wish to thank Dr Haiyong $\mathrm{Gu}$ for technical guidance.

\section{References}

1. Jemal A, Bray F, Center MM, Ferlay J, Ward E and Forman D: Global cancer statistics. CA Cancer J Clin 61: 69-90, 2011.

2. Stanley M: HPV - immune response to infection and vaccination. Infect Agent Cancer 5: 19, 2010.

3. Moore EE, Wark JD, Hopper JL, Erbas B, Garland SM and $\mathrm{CeCaGeEn}$ Study Group: The roles of genetic and environmental factors on risk of cervical cancer: a review of classical twin studies. Twin Res Hum Genet 15: 79-86, 2012.

4. Zoodsma M, Sijmons RH, de Vries EG and Zee AG: Familial cervical cancer: case reports, review and clinical implications. Hered Cancer Clin Pract 2: 99-105, 2004.

5. Wank R and Thomssen C: High risk of squamous cell carcinoma of the cervix for women with HLA-DQw3. Nature 352: 723-725, 1991.

6. Rahimifar S, Erfani N, Sarraf Z and Ghaderi A: ctla-4 gene variations may influence cervical cancer susceptibility. Gynecol Oncol 119: 136-139, 2010.

7. Matsumoto K, Oki A, Satoh T, et al: Interleukin-10 -1082 gene polymorphism and susceptibility to cervical cancer among Japanese women. Jpn J Clin Oncol 40: 1113-1116, 2010.

8. Satinder K, Chander SR, Pushpinder K, Indu G and Veena J: Cyclin D1 (G870A) polymorphism and risk of cervix cancer: a case control study in north Indian population. Mol Cell Biochem 315: 151-157, 2008.

9. Teft WA, Kirchhof MG and Madrenas J: A molecular perspective of CTLA-4 function. Annu Rev Immunol 24: 65-97, 2006.

10. Buonavista N, Balzano C, Pontarotti P, Le Paslier D and Golstein P: Molecular linkage of the human CTLA4 and CD28 Ig-superfamily genes in yeast artificial chromosomes. Genomics 13: 856-861, 1992.

11. Ligers A, Teleshova N, Masterman T, Huang WX and Hillert J: CTLA-4 gene expression is influenced by promoter and exon 1 polymorphisms. Genes Immun 2: 145-152, 2001.

12. Egen JG, Kuhns MS and Allison JP: CTLA-4: new insights into its biological function and use in tumor immunotherapy. Nat Immunol 3: 611-618, 2002.

13. Leach DR, Krummel MF and Allison JP: Enhancement of antitumor immunity by CTLA-4 blockade. Science 271: 1734-1736, 1996.

14. Hurwitz AA, Foster BA, Kwon ED, et al: Combination immunotherapy of primary prostate cancer in a transgenic mouse model using CTLA-4 blockade. Cancer Res 60: 2444-2448, 2000.

15. Curran MA and Allison JP: Tumor vaccines expressing flt 3 ligand synergize with ctla-4 blockade to reject preimplanted tumors. Cancer Res 69: 7747-7755, 2009.

16. Hou R, Cao B, Chen Z, Li Y, et al: Association of cytotoxic T lymphocyte-associated antigen- 4 gene haplotype with the susceptibility to gastric cancer. Mol Biol Rep 37: 515-520, 2010.

17. Sun T, Zhou Y, Yang M, et al: Functional genetic variations in cytotoxic T-lymphocyte antigen 4 and susceptibility to multiple types of cancer. Cancer Res 68: 7025-7034, 2008.

18. Lang C, Chen L and Li S: Cytotoxic T-lymphocyte antigen-4 $+49 \mathrm{G} / \mathrm{A}$ polymorphism and susceptibility to pancreatic cancer. DNA Cell Biol 31: 683-687, 2012.

19. Karabon L, Pawlak-Adamska E, Tomkiewicz A, et al: Variations in suppressor molecule ctla-4 gene are related to susceptibility to multiple myeloma in a polish population. Pathol Oncol Res 18: 219-226, 2012. 
20. Karabon L, Pawlak E, Tomkiewicz A, et al: CTLA-4, CD28, and ICOS gene polymorphism associations with non-small-cell lung cancer. Hum Immunol 72: 947-954, 2011.

21. Kamesh L, Heward JM, Williams JM, et al: CT60 and +49 polymorphisms of CTLA 4 are associated with ANCA-positive smal vessel vasculitis. Rheumatology (Oxford) 48: 1502-1505, 2009.

22. Heidari A, Noori Daloii MR, Keramatipour M, Rashikinezhad A, Sahmani AA and Amirzargar AA: CTLA-4 gene polymorphisms $(-318 \mathrm{C} / \mathrm{T},+49 \mathrm{~A} / \mathrm{G},+6230 \mathrm{~A} / \mathrm{G})$ in Iranian patients with multiple sclerosis. Iran J Allergy Asthma Immunol 9: 219-223, 2010.

23. Li H, Zhou YF, Guo HY, Sun T, Zhang WH and Lin DX: Association between CTLA-4 gene polymorphism and susceptibility to cervical cancer. Zhonghua Zhong Liu Za Zhi 33: 681-684, 2011 (In Chinese)

24. Jiang L, Luo RY, Zhang W, Wang LR, Wang F and Cheng YX: Single nucleotide polymorphisms of CTLA4 gene and their association with human cervical cancer. Zhonghua Yi Xue Yi Chuan Xue Za Zhi 28: 313-317, 2011 (In Chinese).

25. Hu L, Liu J, Chen X, et al: CTLA-4 gene polymorphism +49 A/G contributes to genetic susceptibility to two infection-related cancers - hepatocellular carcinoma and cervical cancer. Hum Immunol 71: 888-891, 2010.

26. Ivansson EL, Juko-Pecirep I and Gyllensten UB: Interaction of immunological genes on chromosome $2 \mathrm{q} 33$ and IFNG in susceptibility to cervical cancer. Gynecol Oncol 116: 544-548, 2010.

27. Pawlak E, Karabon L, Wlodarska-Polinska I, et al: Influence of CTLA-4/CD28/ICOS gene polymorphisms on the susceptibility to cervical squamous cell carcinoma and stage of differentiation in the Polish population. Hum Immunol 71: 195-200, 2010.
28. Castro FA, Haimila K, Sareneva I, et al: Association of HLA-DRB1, interleukin-6 and cyclin D1 polymorphisms with cervical cancer in the Swedish population - a candidate gene approach. Int J Cancer 125: 1851-1858, 2009.

29. Su TH, Chang TY, Lee YJ, et al: CTLA-4 gene and susceptibility to human papillomavirus-16-associated cervical squamous cell carcinoma in Taiwanese women. Carcinogenesis 28: 1237-1240, 2007.

30. Vriens D, de Wilt JH, van der Wilt GJ, Netea-Maier RT, Oyen WJ and de Geus-Oei LF: The role of $\left[{ }^{18} \mathrm{~F}\right]-2$-fluoro-2 -deoxy-d-glucose-positron emission tomography in thyroid nodules with indeterminate fine-needle aspiration biopsy: systematic review and meta-analysis of the literature. Cancer 117: 4582-4594, 2011.

31. Pereira TV, Rudnicki M, Pereira AC, Pombo-de-Oliveira MS and Franco RF: 5,10-Methylenetetrahydrofolate reductase polymorphisms and acute lymphoblastic leukemia risk: a meta-analysis. Cancer Epidemiol Biomarkers Prev 15: 1956-1963, 2006.

32. Sousa H, Santos AM, Pinto D and Medeiros R: Is the p53 codon 72 polymorphism a key biomarker for cervical cancer development? A meta-analysis review within European populations. Int J Mol Med 20: 731-741, 2007.

33. de Freitas AC, Gurgel AP, Chagas BS, Coimbra EC and do Amaral CM: Susceptibility to cervical cancer: an overview. Gynecol Oncol 126: 304-311, 2012. 